GOVERNANCE AND THE EFFICIENCY

OF ECONOMIC SYSTEMS

GESY

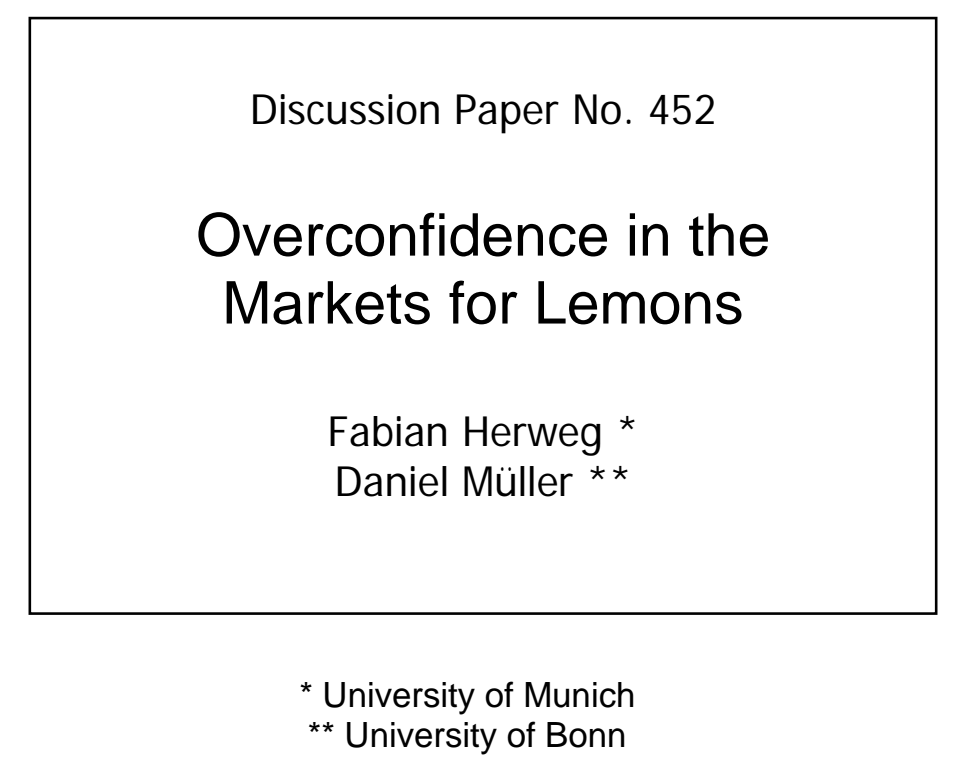

December 2013

Financial support from the Deutsche Forschungsgemeinschaft through SFB/TR 15 is gratefully acknowledged. 


\title{
Overconfidence in the Markets for Lemons*
}

\author{
FABIAN HERWEG ${ }^{\dagger}$ AND DANIEL MÜLleR ${ }^{\ddagger}$
}

December 17, 2013

\begin{abstract}
We extend Akerlof (1970)'s "Market for Lemons" by assuming that some buyers are overconfident. Buyers in our model receive a noisy signal about the quality of the good that is on display for sale. Overconfident buyers do not update according to Bayes' rule but take the noisy signal at face value. We show that the presence of overconfident buyers can stabilize the market outcome by preventing total adverse selection. This stabilization, however, comes at a cost: rational buyers are crowded out of the market.
\end{abstract}

JEL classification: D82; L15

Keywords: Adverse Selection; Market for Lemons; Overconfidence

\section{INTRODUCTION}

There are many markets for used goods that seem to work quite well. In particular nowadays in the age of the Internet, there exist many platforms where tremendous amounts of used goods of all kinds are traded, most prominently eBay. For instance, the trade volume of eBay Motors in the United States is approximately 36000 cars sold each month (Lewis, 2011). Markets for used goods, in particular used cars where stakes are relatively high, having a high volume of trade is puzzling from the perspective of standard economics. It seems reasonable to presume that the potential seller of a used commodity, say a used car, has a good idea of the quality of her car, whereas the potential buyer obtains only little information whether the car on display is a "lemon" or a "cream puff". Given this information structure, standard models of adverse selection predict that only low-quality goods are traded in equilibrium and that the volume of trade is low (Akerlof, 1970). In the extreme, the asymmetric information problem can lead to a complete market breakdown. A

\footnotetext{
${ }^{*}$ We have benefited from comments made by Johannes Maier, Takeshi Murooka, Piers Trepper, and Xiaoyu Xia. All errors are of course our own.

${ }^{\dagger}$ University of Munich, Department of Economics, Ludwigstr. 28, D-80539 Munich, Germany, E-mail address: fabian.herweg@lrz.uni-muenchen.de

${ }_{\ddagger}^{\ddagger}$ University of Bonn, Department of Economics, Chair of Business Administration II, Adenauerallee 2442, D-53113 Bonn, Germany, E-mail address: daniel.mueller@uni-bonn.de, Tel: +49-228-739212, Fax: +49-228-739210 (corresponding author).
} 
seller who owns a cream puff prefers not to offer her car on the market, which reduces the average quality in the market and in turn the trade volume. Besides casual observations that markets for used goods function well, also empirical works investigating markets for used cars find only weak evidence for adverse selection (Bond, 1982; Genesove, 1993).

We provide one possible explanation for this puzzling gap between theoretical predictions and empirical observations by positing that buyers might be overconfident in the following sense: an overconfident buyer believes that he can judge the quality of the good by inspecting it, when in fact he only receives a noisy signal about the good's true quality. For instance, the buyer might consider himself as an expert for used cars and thus believes that after a test drive he knows whether the car is a lemon or a cream puff. A short test drive, however, not necessarily reveals whether the car was involved in an accident and cosmetically repaired afterward, so a test drive is a noisy signal at best. We show that if the buyer is overconfident with positive probability, there always exists an equilibrium in which high-quality goods are traded. Moreover, if it is sufficiently likely that the buyer is overconfident, all pure-strategy equilibria are pooling equilibria in which all qualities are traded. The presence of overconfident buyers thus can stabilize the market and helps to prevent the total adverse selection outcome. This market stabilization, however, comes at a cost: rational buyers do not participate in the market anymore. Furthermore, the presence of overconfident buyers can create incentives for sellers to invest in inefficient signal obfuscation-i.e., making the true quality even more shrouded.

We introduce buyer overconfidence in an otherwise standard and fairly simple model of a market with asymmetric information. There is a single seller and a single buyer. The seller, who owns one unit of the good, knows whether her item is of high quality or low quality. The buyer, on the other hand, cannot directly observe the quality of the good but receives a private noisy signal about the quality of the item on display. We focus on highly uninformative signals, so that in the benchmark case where the buyer is a rational Bayesian updater the unique perfect Bayesian equilibrium outcome in pure strategies is total adverse selection: only items of low quality are traded in equilibrium. This benchmark outcome is in contrast to the findings we obtain when the buyer might be overconfident, because then high-quality items are always traded in equilibrium with positive probability.

Related Literature.-Beginning with Akerlof's (1970) seminal contribution, by now there exists a large literature investigating markets with asymmetric information. Analyzing a market with perfectly informed sellers and uninformed buyers, Akerlof (1970) shows that asymmetric information leads to a reduction in the average quality sold in the market and also reduces the trade volume. In the extreme, asymmetric information can 
lead to a market unraveling, i.e., no transaction takes place in equilibrium. Wilson (1980) extends this analysis by demonstrating that equilibrium outcomes crucially depend on the price-setting mechanism. Later contributions focus on how the degree of asymmetric information affects the market outcome. Investigating a market where sellers are not perfectly informed, both Kessler (2001) and Levin (2001) find that market performance behaves non-monotonically in the degree of asymmetric of information. A setting with a monopolistic seller where buyers can purchase information about the quality of the good at display is analyzed by Bester and Ritzberger (2001). They find that as the cost of information becomes small, the unique equilibrium approaches the full information outcome and prices become perfectly revealing. Recent contributions consider the situation where the buyer receives a private signal about the offered quality. Investigating how the signal precision affects the equilibrium outcome, Voorneveld and Weibull (2011) demonstrate that the equilibrium is discontinuous at the boundaries of completely uninformative and completely informative signals. Focusing on the case where it is inefficient to trade goods of poor quality, Adriani and Deidda (2009) show that the unique equilibrium surviving D1 (Cho and Kreps, 1987) is characterized by market breakdown. Finally, Adriani and Deidda (2011) show that strong competition between sellers inhibits the role of prices as signals and drives high-quality sellers out of the market.

A model of asymmetric information with a non-rational buyer is discussed by Eyster and Rabin (2005). The authors develop an equilibrium concept, called cursed equilibrium, where "cursed" players do not take fully into account how other players' actions depend on their private information. Eyster and Rabin show that in a "lemons market" cursedness on the side of the buyer has two opposing effects on the probability with which trade takes place. On the one hand, a cursed buyer expects the good to be of higher quality, because he does not understand that the seller is willing to sell only when her value is low. On the other hand, a cursed buyer does not understand that a higher price increases the expected quality. Whether cursedness leads to more or less trade compared to the rational benchmark depends on the possible gains from trade. If gains from trade are high, the second effect outweighs the first effect and cursedness reduces the probability of trade. In contrast to Eyster and Rabin (2005) we posit that the buyer is overconfident instead of cursed. Moreover, we allow for buyer heterogeneity-in the sense that the buyer can be overconfident or rational-and investigate how the presence of biased buyers affects the well-being of rational buyers.

To the best of our knowledge, there does not exist a paper that incorporates overconfident buyers into a commodity market with asymmetric information. Sandroni and Squintani (2007) introduce overconfident agents into Rothschild and Stiglitz (1976)'s classic 
insurance market. Overconfident agents here believe that their risk is low when indeed it is high. While a compulsory insurance can lead to a Pareto improvement when all insurees are rational, this is no longer the case when a sufficiently large proportion of the insurees is overconfident. Considering a model where consumers are uncertain about their future demand when signing a contract, Grubb (2009) shows that the optimal contract closely resembles a three-part tariff if consumers are overconfident in the sense that they underestimate variations in their future tastes. Next to Industrial Organization, overconfident agents are also introduced to operations management (Crowson, Crowson, and Ren, 2007) and contract theory (Fang and Moscarini, 2005; de la Rosa, 2011).

\section{THE MODEL}

A seller $(S)$ owns one unit of an indivisible good, the quality of which is $q \in\left\{q_{L}, q_{H}\right\}$ with $0 \leq q_{L}<q_{H} \cdot{ }^{1}$ Her reservation price for quality $q$ is $r(q)$, with $r\left(q_{L}\right)=r_{L}$ and $r\left(q_{H}\right)=r_{H}$. The probability of $S$ being endowed with high quality is $\alpha \in(0,1)$. The buyer $(B)$ 's valuation for quality $q, v(q)$, is normalized such that $v\left(q_{L}\right)=q_{L}$ and $v\left(q_{H}\right)=$ $q_{H}$.

\section{Assumption 1.}

(i) $q_{H}-r_{H} \geq q_{L}-r_{L}$

(ii) $q_{L}-r_{L}>0$

(iii) $r_{H}>\bar{q}:=\alpha q_{H}+(1-\alpha) q_{L}$

Assumption 1 (i) and (ii) together guarantee that there are positive gains from trade for all quality levels, an assumption usually imposed in the literature. ${ }^{2}$ Moreover, we are interested in markets in which there is an adverse selection problem in the sense that highquality sellers value the item above the average quality, Assumption 1 (iii). If Assumption 1 (iii) is violated there does always exist a pooling equilibrium. It is important to note that Assumption 1 (iii) implies that $B$ 's willingness to pay for a low-quality item is below the reservation price of a high-quality seller, $q_{L}<r_{H}$.

While $B$ cannot directly observe quality, he receives a private signal $s \in\{L, H\}$, which is positively correlated with true quality, $\gamma=\operatorname{Pr}\left(s=H \mid q=q_{H}\right)=\operatorname{Pr}\left(s=L \mid q=q_{L}\right) \in$ $(1 / 2,1)$. We refer to $s=H$ and $s=L$ as the "good" and the "bad" signal, respectively.

There are two potential types of buyers, $\tau \in\{R, O\}$ : with probability $1-\lambda, B$ is a rational Bayesian updater $(\tau=R)$, who draws the correct informational inference from

\footnotetext{
${ }^{1}$ Modeling the lemons market as a bilateral monopoly is not uncommon in the literature and used, for instance, by Ellingsen (1997). In the benchmark case with a Bayesian buyer, our model is a simplified version of Voorneveld and Weibull (2011) with binary signals.

${ }^{2}$ Assumption 1 (i) is made in order to simplify the exposition.
} 
the signal he receives. With probability $\lambda \in[0,1), B$ is overconfident $(\tau=O)$ in his own ability to judge the quality of the item from his private signal in the sense that he believes the signal to be perfectly informative.

Two prominent notions of overconfidence are overprecision and overestimation. While overprecision refers to people believing their estimates to be more accurate than they actually are, overestimation alludes to people overestimating their own abilities. ${ }^{3}$ Our model captures both these biases: if the buyer wrongly believes his noisy signal to be perfectly accurate, then he is prone to overestimation; if he wrongly believes to be an expert who can perfectly determine the quality of the item on display by inspecting it, then he suffers from overestimation.

Both $S$ and $B$ are risk neutral and maximize expected profit and expected utility, respectively. While $S$ 's profit from selling at price $p$ is $\pi=p-r, B$ 's utility from purchasing quality $q$ at price $p$ is $u=q-p$. If no trade takes place, $S$ 's profit and $B$ 's utility are zero.

The sequence of events is as follows. (i) Nature draws $q \in\left\{q_{L}, q_{H}\right\}$. (ii) $S$ observes $q$ and sets a take-it-or-leave-it price $p \in \mathbb{R}$. A pure strategy for $S$ is a pair $\left(p_{L}, p_{H}\right)$, where $p_{L}\left(p_{H}\right)$ denotes the price for a low-quality (high-quality) item. (iii) Nature draws $\tau \in\{R, O\}$ and $s \in\{L, H\}$. (iv) The buyer sees the price $p$ set by the seller and privately observes the signal $s$. Based on this information, $B$ decides whether to buy the item. A pure strategy for a buyer of type $\tau$ is a function $b^{\tau}: \mathbb{R} \times\{L, H\} \longrightarrow\{0,1\}$, where $b^{\tau}(p, s)=1$ means "buy" and $b^{\tau}(p, s)=0$ means "don't buy" at price $p$ and for signal $s$. (v) Both parties receive their respective payoffs, $\pi=(p-r) b^{\tau}(p, s)$ and $u=(q-p) b^{\tau}(p, s) .^{4}$

We augment the usual notion of (weak) perfect Bayesian equilibrium in pure strategies in order to allow for an overconfident buyer. ${ }^{5}$ Let $\mu_{s}^{\tau}(p)$ denote the belief held by buyer type $\tau$ about high quality being offered when observing price $p$ and receiving signal $s$. Let $\mu^{\tau}=\left\{\left(\mu_{L}^{\tau}(p), \mu_{H}^{\tau}(p)\right) \in[0,1]^{2} \mid p \in \mathbb{R}\right\}$.

Definition 1. A market equilibrium is a vector $\left(\mu^{R}, \mu^{O},\left(p_{L}, p_{H}\right), b^{R}(p, s)\right.$, $\left.b^{O}(p, s)\right)$ that satisfies the following conditions:

(B1) If $p_{L} \neq p_{H}$, then $\mu_{L}^{R}\left(p_{L}\right)=\mu_{H}^{R}\left(p_{L}\right)=0$ and $\mu_{L}^{R}\left(p_{H}\right)=\mu_{H}^{R}\left(p_{H}\right)=1$.

(B2) If $p_{L}=p_{H}=\bar{p}$, then

$$
\mu_{H}^{R}(\bar{p})=\frac{\gamma \alpha}{\gamma \alpha+(1-\gamma)(1-\alpha)} \quad \text { and } \quad \mu_{L}^{R}(\bar{p})=\frac{(1-\gamma) \alpha}{(1-\gamma) \alpha+\gamma(1-\alpha)} .
$$

\footnotetext{
${ }^{3}$ See Alpert and Raiffa (1982) or Soll and Klayman (2004) on overprecision, and Clayson (2005) or Buehler, Griffin, and Ross (1994) on overestimation.

${ }^{4}$ The analysis would remain unchanged if all draws by nature occurred in step (i).

${ }^{5}$ Focusing on pure-strategy equilibria often allows us to obtain a unique equilibrium outcome without applying any equilibrium refinement.
} 
(B3) For all $p \in \mathbb{R}$ and $s \in\{L, H\}, \mu_{L}^{O}(p)=0$ and $\mu_{H}^{O}(p)=1$.

(SR) At each information set, the concerned player's strategy is a best response to the other player's strategy under the belief induced by $\mu$ at that information set.

(B1) and (B2) specify a rational buyer's beliefs on the equilibrium path: if $S$ charges different prices for different qualities, an incompletely informed rational buyer shouldirrespective of the signal he receives-believe the item to be of low quality if he observes price $p_{L}$ and of high quality if he observes price $p_{H}$; if $S$ charges the same price for both high-quality and low-quality items, then a rational buyer's beliefs are determined by Bayes' rule. (B3) specifies that an overconfident buyer takes the signal at face value irrespective of the price. Last, (SR) requires sequential rationality.

Finally, let $\rho_{L}$ and $\rho_{H}$ denote the trading probabilities in equilibrium for low-quality and high-quality goods, respectively.

\section{The ANALYSis}

The following observations hold irrespective of $B$ 's type: first, sequential rationality requires $b^{\tau}(p, s)=1$ for $p \leq q_{L}$ and $b^{\tau}(p, s)=0$ for $p>q_{H}$. Thus, in any equilibrium low quality must be traded with strictly positive probability at a price of at least $q_{L}$ and at most $q_{H}$-otherwise $S$ could profitably deviate to $p=q_{L}$. Likewise, high quality will never be priced strictly below $r_{H}$ because $S$ could profitably deviate to $p>q_{H}$. Hence, there are three kinds of equilibrium candidates: (i) pooling equilibrium, i.e., $p_{L}=p_{H}=\bar{p} \in\left[r_{H}, q_{H}\right]$, (ii) separating equilibrium with trade of high-quality items, i.e., $p_{L}=q_{L}$ and $p_{H} \in\left[r_{H}, q_{H}\right]$ and (iii) separating equilibrium without trade of highquality items (total adverse selection), i.e., $p_{L}=q_{L}$ and $p_{H} \geq q_{H}{ }^{6}$

\subsection{No Overconfidence and Total Adverse Selection}

In this subsection we analyze, as a benchmark, the case where the buyer is a rational Bayesian updater with certainty, i.e. $\lambda=0$. If the signal is sufficiently imprecise, then no pooling equilibrium exists. Intuitively, with $\bar{q}<r_{H}, B$ purchases at the pooling price $\bar{p} \geq r_{H}$ only if he receives positive information about the quality on display, i.e., $s=H$. If the signal is highly uninformative, however, then $B$ 's willingness to pay after receiving $s=H$ is below $r_{H}$ and thus no pooling equilibrium exists.

\footnotetext{
${ }^{6}$ If the buyer is overconfident with positive probability, there may exist another type of separating equilibrium with trade of high-quality items. A low-quality seller sells at a higher price than a high-quality seller. While the low-quality seller sells only to an overconfident buyer who received a good signal, the high-quality seller sells also to a rational buyer. The proof of Proposition 2 shows that such an equilibrium does not exist.
} 
Lemma 1. Suppose that Assumption 1 holds. For $\lambda=0$ there does not exist a purestrategy pooling equilibrium if

$$
\gamma<\tilde{\gamma}:=\frac{\left(r_{H}-q_{L}\right)(1-\alpha)}{\left(q_{H}-r_{H}\right) \alpha+\left(r_{H}-q_{L}\right)(1-\alpha)} \in\left(\frac{1}{2}, 1\right) .
$$

Moreover, for a sufficiently imprecise signal there does not exist a separating equilibrium with trade of high-quality items. Intuitively, a pure-strategy separating equilibrium is most likely to exist if $B$ purchases the high-quality item only after receiving $s=H$, which requires that $p_{H}=q_{H}$. Even if $B$ follows this strategy, however, a low-quality seller can profitably mimic a high-quality seller if $B$ receiving a good signal is sufficiently likely to occur also in the case of low quality.

Lemma 2. Suppose that Assumption 1 holds. For $\lambda=0$ there does not exist a purestrategy separating equilibrium with $\rho_{H}>0$ if

$$
\gamma<\hat{\gamma}:=\frac{q_{H}-q_{L}}{q_{H}-r_{L}} \in\left(\frac{1}{2}, 1\right)
$$

In what follows, we restrict attention to a rather noisy signal such that in the benchmark case high quality is not traded in equilibrium.

Assumption 2. $\gamma<\min \{\hat{\gamma}, \tilde{\gamma}\}$.

We can always support a separating equilibrium without trade of high quality - this is most obvious for pessimistic out-of-equilibrium beliefs, i.e., $\mu_{s}^{R}(p)=0$ for all $p \neq p_{H}$ and $s \in\{L, H\}$. Thus, for a fairly noisy signal, the market exhibits the well-known adverse selection problem (Akerlof, 1970).

Proposition 1. Suppose Assumptions 1 and 2 hold. For $\lambda=0$, in all pure-strategy equilibria it holds that $p_{L}=q_{L}, p_{H} \geq q_{H}, \rho_{L}=1$ and $\rho_{H}=0$.

\subsection{Overconfidence and Market Stabilization}

Now, we posit that the buyer is overconfident with probability $\lambda \in(0,1)$. The first observation is that total adverse selection is not a feasible equilibrium outcome if there are overconfident buyers in the market. A seller of high quality can always ask for a price higher than her reservation value $-p_{H} \in\left(r_{H}, q_{H}\right]$ - that allows her to sell with positive probability because she sells at least to an overconfident buyer who receives a good signal. Even if there are only few overconfident buyers and even if the signal is fairly noisy, this strategy leads to strictly positive profits in expectations. Thus, if there exists a purestrategy equilibrium, then both qualities are traded in this equilibrium. In the following, we characterize this equilibrium and establish conditions for its existence. 
First, we show the existence of a pooling equilibrium in which high-quality items are traded with strictly positive probability even when the signal is very uninformative, i.e., Assumption 2 holds. In any pooling equilibrium with trade of high quality we must have $\bar{p} \in\left[r_{H}, q_{H}\right]$. Upon observing price $\bar{p}$, beliefs of a rationally updating buyer are determined according to $(B 2)$, whereas beliefs of an overconfident buyer are given by (B3). In consequence, upon observing price $\bar{p}$ and signal $s \in\{H, L\}$, a rational buyer purchases the item if

$$
\bar{p} \leq \bar{q}(s) \equiv \mu_{s}(\bar{p}) q_{H}+\left[1-\mu_{s}(\bar{p})\right] q_{L} .
$$

Thus, for $\gamma<\tilde{\gamma}$, a rational buyers does not purchase at price $\bar{p}$ because $\bar{q}(L)<\bar{q}(H)<$ $r_{H}$. An overconfident buyer, on the other hand, purchases if $\bar{p} \leq q_{s}$, and therefore buys the item at price $\bar{p}$ if he receives $s=H$. Hence, irrespective of her item's quality, for any price $\bar{p} \in\left[r_{H}, q_{H}\right)$ the seller has an incentive to deviate to the highest price at which trade possibly takes place, such that the only price consistent with a pooling equilibrium is $\bar{p}=q_{H}$. To establish existence of a pooling equilibrium with price $\bar{p}=q_{H}$, consider pessimistic out-of-equilibrium beliefs for a rational buyer, i.e., $\mu_{s}(p)=0$ for all $p \neq \bar{p}$ and $s \in\{L, H\}$. Since the seller of a low-quality item can always sell for sure at a price $q_{L}, \bar{p}=q_{H}$ can only be part of a pooling equilibrium if $q_{L}-r_{L} \leq \lambda(1-\gamma)\left(q_{H}-r_{L}\right)$, or equivalently, if

$$
\lambda \geq \frac{q_{L}-r_{L}}{(1-\gamma)\left(q_{H}-r_{L}\right)}=: \bar{\lambda} .
$$

Note that $\gamma<\hat{\gamma}$ implies $\bar{\lambda}<1$. Since a high-quality seller obviously has no reason to deviate, there exists a pooling equilibrium even for a fairly noisy signal as long as the share of overconfident buyers is sufficiently large.

Proposition 2. Suppose that Assumptions 1 and 2 hold. Then, for $\lambda \in(0,1)$ there does not exist a pure-strategy separating equilibrium. If $\lambda \geq \bar{\lambda}$, then there exists a pure-strategy pooling equilibrium with a price $p_{L}=p_{H}=q_{H}$ and trading probabilities $\rho_{L}=\lambda(1-\gamma)$ and $\rho_{H}=\lambda \gamma$.

From the above proposition, the next result-for the case with almost no gains from trade for low-quality items-follows immediately.

Corollary 1. Suppose that Assumptions 1 and 2 hold and that $q_{L} \rightarrow r_{L}$. Then, for $\lambda \in$ $(0,1)$ there always exists a pure-strategy equilibrium and any pure-strategy equilibrium is a pooling equilibrium.

According to Corollary 1, if the low-quality item is basically useless, then an arbitrary small proportion of overconfident buyers in the market is sufficient to avoid the undesirable total adverse selection outcome. 


\subsection{Market Efficiency}

So far we have shown that the presence of overconfident buyers can help to avoid the total adverse selection outcome. It thus stands to reason that the presence of overconfident buyers can also improve market efficiency. Given the buyer is overconfident with probability $\lambda$, then market efficiency, defined as expected gains from trade, is

$$
W(\lambda)=\alpha \rho_{H}(\lambda)\left(q_{H}-r_{H}\right)+(1-\alpha) \rho_{L}(\lambda)\left(q_{L}-r_{L}\right)
$$

Comparison of $W(0)$ and $W(\lambda)$ (with $\lambda \geq \bar{\lambda}$ ) reveals that the presence of overconfident buyers in the market tends to increase market efficiency if (i) there are many sellers with a high-quality good who otherwise would not offer their goods on the market, (ii) there are many overconfident buyers willing to buy the good in case of a good signal, and (iii) gains from trade are much higher for a high-quality than for a low-quality item. In particular, as gains from trading low quality become small, $q_{L} \rightarrow r_{L}$, then buyer overconfidence strictly improves market efficiency.

\subsection{Equilibrium in Mixed Strategies}

One question is immediately at hand from Proposition 2: What happens for $\lambda<\bar{\lambda}$, i.e., if neither a pure-strategy pooling equilibrium nor a pure-strategy separating equilibrium exists? In this case, there exists a mixed-strategy separating equilibrium with trade of high-quality items. The equilibrium prices are $p_{L}=q_{L}$ and $p_{H}=q_{H}$. With pessimistic out-of-equilibrium beliefs for a rational buyer, in one type of equilibrium the buyer plays the following mixed strategy: $b^{R}\left(p_{H}, H\right)=\sigma \in(0,1), b^{R}(p, s)=1$ for $p \leq q_{L}$, and $b^{R}(p, s)=0$ in the remaining cases. If the mixing probability $\sigma$ is sufficiently small, then the low-quality seller has no incentives to mimic the high-quality seller. For pessimistic out-of-equilibrium beliefs the mixing probability has to satisfy

$$
\sigma \leq \frac{\bar{\lambda}-\lambda}{1-\lambda}=: \bar{\sigma}
$$

As is intuitive, with a low-quality seller's incentive to deviate being increasing in the share of overconfident buyers, the maximum mixing probability decreases in $\lambda$. In this equilibrium, rational buyers as well as overconfident buyers and both types of sellers are active. In this mixed-strategy equilibrium, the maximum trading probability for high quality is

$$
\bar{\rho}_{H}(\lambda)=\gamma[\lambda+(1-\lambda) \bar{\sigma}]=\gamma \bar{\lambda},
$$

and does not depend on $\lambda$. Thus, in this mixed-strategy equilibrium the presence of overconfident buyers leaves market efficiency unaffected. Notice that this mixed strategy equilibrium exists also in the benchmark case with $\lambda=0$. In this equilibrium rational buyers 
are skeptical when observing a high price and therefore buy only once in a while-even though they know that the good is of high quality on the equilibrium path. Moreover, the rational buyer has to be sufficiently skeptical in order to stabilize this kind of equilibrium. Therefore, we believe that as long as a pure-strategy equilibrium exists, this is the more plausible prediction than the described mixed-strategy equilibrium.

\subsection{Obfuscation}

So far, we abstracted from the possibility that a seller might be able to influence the quality of the signal the buyer receives. One can imagine, however, that the seller can invest into obfuscating the quality of the car and this is unobservable to the buyer, i.e., by investing the seller makes the signal noisier. For instance, the seller might clean and polish the car in order to pretend that she always handled the car with due care. With polishing the car only for sale being costly and unobservable, if all buyers are rational no seller should have an incentive to display a car which looks well-kempt even though it is not to a potential buyer. If some buyers are overconfident, on the other hand, then it might well be rational for a seller to polish her car. In the following we briefly analyze the seller's incentives to invest in signal obfuscation and the resulting welfare effects.

Suppose the seller can-after observing her type-invest in signal obfuscation at cost $c>0$, i.e., the seller chooses $I \in\{0,1\}$. The seller's investment, which is not observed by the buyer, affects the signal precision, $\gamma_{I}$ for $I \in\{0,1\}$. Let $\gamma_{1}<\gamma_{0}<\min \{\tilde{\gamma}, \hat{\gamma}\}$ and $\lambda \geq \bar{\lambda}$. Independent of the seller's investment decision, the unique pure-strategy equilibrium is the one described in Proposition 2: $p_{H}=p_{L}=q_{H}, \rho_{L}=\lambda\left(1-\gamma_{I}\right)$ and $\rho_{H}=\lambda \gamma_{I}$. Obviously, a high-quality seller has no incentives to invest in signal obfuscation because this reduces her trading probability and is costly. A low-quality seller, on the other hand, may have an incentive to invest in quality obfuscation because it increases her trading probability. The low-quality seller invests if and only if

$$
\bar{c}:=\lambda\left(q_{H}-r_{L}\right)\left(\gamma_{0}-\gamma_{1}\right) \geq c
$$

The investment is undesirable from the buyer's point of view but can be desirable from a welfare point of view, since it increases the trading probability. Private benefits from investment, however, diverge from social benefits of investment. From a welfare point of view the investment is desirable if and only if

$$
\hat{c}:=\lambda\left(q_{L}-r_{L}\right)\left(\gamma_{0}-\gamma_{1}\right) \geq c
$$

Note that $\hat{c}<\bar{c}$, so there exists a range of investment costs where a low-quality seller invests in signal obfuscation and this is undesirable from a welfare point of view. This 
range is particularly large if the gains from trading a low-quality item are negligible, i.e., for $q_{L} \rightarrow r_{L}$ we have $\hat{c} \rightarrow 0$. Thus, in the case where without investment opportunities the presence of overconfident buyers unambiguously improves market efficiency it leads to undesirable investments in obfuscation if these investments are feasible. The positive effect that buyer overconfidence has on the trading probability and thus welfare can be outweighed by the negative effect it has on investments- the negative effect is likely to be more important if the seller is likely to possess an item of low quality, i.e., if $\alpha$ is low. In summary, how the presence of overconfident buyers affects market performance is not clear in general, because there are several opposing effects.

\section{CONCLUSION}

We introduce overconfident buyers into an otherwise standard model of asymmetric information, where the seller is better informed about the quality of the good than the buyer. Buyer overconfidence in our model can be interpreted as either overprecision or overestimation. We show that if the proportion of overconfident buyers is not too small, then the unique equilibrium outcome is a pooling equilibrium with trade of both high-quality and low-quality goods. If, on the other hand, all buyers are rational Bayesian updater, then the unique equilibrium outcome is total adverse selection: only "lemons" are traded on the market. The presence of overconfident buyers thus leads to also "cream puffs" being traded, which is likely to increase market performance-in particular if gains from trading lemons are small compared to gains from trading cream puffs.

One might wonder how robust the finding is that the presence of overconfident buyers increases market performance. The presence of overconfident buyers can enhance market performance not only by preventing total adverse selection. It can be shown that if there exists a separating equilibrium with trade of high-quality items in pure strategies, then the presence of overconfident buyers can increase market performance. Without overconfident buyers, rational buyers purchase high-quality items only after observing a good signal. If there are many overconfident buyers, then there also exists a separating equilibrium where rational buyers always purchase a high-quality item.

Finally, we studied a fairly stylized model which abstracts from many issues that might play a crucial role in practice. Arguably the strongest simplification is that an overconfident buyer takes the signal at face value. From this assumption it follows almost immediately that total adverse selection is no longer an equilibrium outcome. How the presence of overconfident buyers affects the equilibrium outcome and Bayesian buyers is less clear, however. The contribution of this paper is it to provide an answer to these questions. With a less extreme form of overconfidence the analysis is more intricate and there are typically 
multiple pure-strategy equilibria. Suppose an overconfident buyer knows that the signal is only a noisy measure of the good's actual quality but wrongly believes that the signal is more precise than it actually is, i.e., the overconfident buyer believes that $\gamma$ is larger. In such a model it is necessary to formulate out-of-equilibrium beliefs also for an overconfident buyer. A direct implication of this is that there exists a set of out-of-equilibrium beliefs so that the equilibrium outcome is total adverse selection. Our notion captures, in an extreme way, the idea that biased agents trust more in the information they receive than in the abstract believes they have formed about the behavior of other market participants.

\section{A. Proofs of Propositions And Lemmas}

Proof of Lemma 1. Suppose, in contradiction, that the price $\bar{p}$ constitutes a pooling equilibrium. We know that we must have $\bar{p} \in\left[r_{H}, q_{H}\right]$. Given price $\bar{p}$, a rational buyer's belief about the item being of high quality after receiving signal $s \in\{L, H\}$ is given by $\mu_{s}(\bar{p})$ according to $(B 2)$ and he will buy the item if and only if

$$
\bar{p} \leq \mu_{s}(\bar{p}) q_{H}+\left(1-\mu_{s}(\bar{p})\right) q_{L}=: \bar{q}(s) .
$$

Since $\bar{q}(L)<\bar{q}<r_{H}$, for a pooling equilibrium with trade of high-quality items to exist, we must have $\bar{p} \in\left[r_{H}, \bar{q}(H)\right]$. Put differently, if a pooling equilibrium exists then the buyer will purchase the item only after receiving the good signal $s=H$. Note that $\lim _{\gamma \searrow 1 / 2} \bar{q}(H)=\bar{q}, \lim _{\gamma \nearrow 1} \bar{q}(H)=q_{H}$, and $d \bar{q}(H) / d \gamma>0$. Hence, by the intermediatevalue theorem, there exists a unique value $\tilde{\gamma}$ such that $\bar{q}(H)=r_{H}$.

Finally, note that $\tilde{\gamma}>1 / 2$, or equivalently

$$
(1-\alpha)\left(r_{H}-q_{L}\right)>\alpha\left(q_{H}-r_{H}\right)
$$

by Assumption 1 (iii), which concludes the proof.

Proof of Lemma 2. First, according to $(B 1)$, in any separating equilibrium with equilibrium prices $p_{L} \neq p_{H}$ we have $\mu_{s}\left(p_{L}\right)=0$ and $\mu_{s}\left(p_{H}\right)=1$ for $s \in\{L, H\}$. This implies that $p_{L}=q_{L}$ : if $p_{L}>q_{L}$, then the buyer would not buy and the seller of a lowquality item could profitably deviate to a price $p \in\left(r_{L}, q_{L}\right]$, thereby selling for sure; if $p_{L}<q_{L}$, then the seller of a low-quality item could profitably deviate to $p=q_{L}$, thereby still selling for sure at a higher price. Next, whenever a high-quality seller sells with strictly positive probability in equilibrium, i.e., $\rho_{H}>0$, we must have $p_{H} \in\left[r_{H}, q_{H}\right]$. Note that, since $\mu_{s}\left(p_{H}\right)=1$, sequential rationality requires that the buyer always buys for $p_{H} \in\left[r_{H}, q_{H}\right)$. This, however cannot be part of any equilibrium because a low-quality seller could profitably deviate to price $p_{H}$. Therefore. in any separating equilibrium in 
which the seller of a high-quality item sells with strictly positive probability, we have $\rho_{H}<1$ and thus $p_{H}=q_{H}$ (because $B$ has to be indifferent between buying and not buying at price $\left.p_{H}\right)$. With our focus on pure strategies, for $\rho_{H}<1$ to be feasible, the buyer has to condition his purchasing decision at price $p_{H}$ on the realization of the signal he receives, i.e., $b\left(p_{H}, s\right)=1$ for $s \in \mathcal{B} \subset\{L, H\}$ and $b\left(p_{H}, s\right)=0$ for $s \in\{L, H\} \backslash \mathcal{B}$. With $\operatorname{Pr}\left(H \mid q_{L}\right)<\operatorname{Pr}\left(L \mid q_{L}\right)$, the seller of a low-quality item will deviate to $p_{H}=q_{H}$ if $\operatorname{Pr}\left(H \mid q_{L}\right)\left(q_{H}-r_{L}\right)>\left(q_{L}-r_{L}\right)$, or equivalently, if $\gamma<\hat{\gamma}$. Noting that $\hat{\gamma}>1 / 2$ if and only if $q_{H}-q_{L}>q_{L}-r_{L}$, which holds by Assumption 1, completes the proof.

Proof of Proposition 1. We show that a separating equilibrium without trade of highquality items always exist. The proposition follows from this observation together with Lemmas 1 and 2.

In an adverse selection equilibrium, we must have $p_{L}=q_{L}, p_{H} \geq q_{H}$, and $\mu_{s}\left(p_{L}\right)=0$ and $\mu_{s}\left(p_{H}\right)=1$ for $s \in\{L, H\}$. With buyer behavior for prices $p \leq q_{L}$ and $p>q_{H}$ not depending on the buyer's beliefs, in order to support the equilibrium under consideration, we have to specify out-of-equilibrium beliefs for prices $p \in\left(q_{L}, q_{H}\right]$ such that neither type of seller has an incentive to deviate. One set of beliefs doing the job is given by $\mu_{s}(p) \leq$ $\left(p-q_{L}\right) /\left(q_{H}-q_{L}\right)$ for $p \in\left(q_{L}, q_{H}\right]$ and $s \in\{L, H\}$. Since $\mu_{s}(p) q_{H}+\left(1-\mu_{s}(p)\right) q_{L}-p \leq 0$ it is sequentially rational for the buyer never to buy at prices $p \in\left(q_{L}, q_{H}\right]$, which in turn implies that no type of seller has an incentive to deviate to such prices. ${ }^{7}$

Proof of Proposition 2. Existence of a pooling equilibrium for $\lambda \geq \bar{\lambda}$ is established in the main text. It remains to show that there does not exist a pure-strategy separating equilibrium with trade of high-quality items. There are two potential kinds of pure-strategy separating equilibria:

(i) The standard separating equilibrium with trade of high-quality items, where $p_{L}=q_{L}$ and $p_{H} \in\left[r_{H}, q_{H}\right]$. This kind of equilibrium is most likely to exist if the Bayesian buyer has pessimistic out-of-equilibrium beliefs and purchases at $p_{H}$ only after receiving $s=H$. This strategy is sequentially rational only for $p_{H}=q_{H}$. Moreover, we know that $p_{L}=q_{L}$. If the Bayesian buyer uses this strategy, then he behaves (on the equilibrium path) exactly as an overconfident buyer. Thus, the incentives to deviate to $p=q_{H}$ for a seller who possesses a good of low quality are independent of the probability with which she faces an overconfident buyer. Hence, it follows immediately from Lemma 2 that a low-quality seller prefers to deviate if $\gamma<\hat{\gamma}$. Thus, there does not exist a pure-strategy separating equilibrium if Assumption 2 holds.

\footnotetext{
${ }^{7}$ Here, it is assumed that the buyer does not purchase the high-quality item if he is indifferent. If we assumed otherwise, i.e., the buyer purchases with strictly positive probability in the case of indifference, then in all pure-strategy equilibria it holds that $p_{H}>q_{H}$. Also, the out-of-equilibrium beliefs specified above for prices $p \in\left(q_{L}, q_{H}\right]$ have to be adjusted to $\mu_{s}(p)<\left(p-q_{L}\right) /\left(q_{H}-q_{L}\right)$.
} 
(ii) For pessimistic out-of-equilibrium beliefs there may exist a separating equilibrium in which $p_{L}=q_{H}$ and $p_{H} \in\left[r_{H}, q_{H}\right)$. Low-quality sellers sell only to overconfident buyers who received signal $s=H$. High-quality sellers also trade (always) with Bayesian buyers, since $p_{H}<q_{H}$ and the price signals the quality.

In such an equilibrium, a low-quality seller cannot capitalize on mimicking a highquality seller if

$$
\begin{gathered}
\lambda(1-\gamma)\left(q_{H}-r_{L}\right) \geq[1-\lambda+\lambda(1-\gamma)]\left(p_{H}-r_{L}\right) \\
\Longleftrightarrow \quad \lambda \geq \frac{p_{H}-r_{L}}{q_{H}-r_{L}-\gamma\left(q_{H}-p_{H}\right)} \equiv \hat{\lambda}_{1}(\gamma) .
\end{gathered}
$$

The lower bound, $\hat{\lambda}_{1}(\gamma)$, is increasing in $\gamma$. A high-quality seller does not want to switch to $p=q_{H}=p_{L}$ if

$$
\begin{array}{r}
\lambda(1-\lambda+\lambda \gamma)\left(p_{H}-r_{H}\right) \geq \lambda \gamma\left(q_{H}-r_{H}\right) \\
\Longleftrightarrow \quad \lambda \leq \frac{p_{H}-r_{H}}{p_{H}-r_{H}+\gamma\left(q_{H}-p_{H}\right)} \equiv \hat{\lambda}_{2}(\gamma),
\end{array}
$$

with $\hat{\lambda}_{2}(\gamma)$ being decreasing. The equilibrium exists only if $\hat{\lambda}_{1}(\gamma) \leq \lambda \leq \hat{\lambda}_{2}(\gamma)$, which is most likely to be satisfied if $\gamma \rightarrow 1 / 2$. Thus, there does not exist a such a separating equilibrium if $\chi\left(r_{L}\right)>\chi\left(r_{H}\right)$ where

$$
\chi(x) \equiv \frac{2\left(p_{H}-x\right)}{q_{H}+p_{H}-2 x} .
$$

Note that $q_{H}>p_{H}$ implies that $\chi^{\prime}(x)<0$, which completes the proof.

Proof of Corollary 1. The result follows from Proposition 2 and the fact that $\bar{\lambda} \rightarrow 0$ if $q_{L} \rightarrow r_{L}$.

\section{REFERENCES}

AdRIANI, F., AND L. G. DEIDDA (2009): "Price signaling and the strategic benefits of price rigidities," Games and Economic Behavior, 67, 335-350.

(2011): "Competition and the Signaling Role of Prices," International Journal of Industrial Organization, 29, 412-425.

AKERlOF, G. A. (1970): "The market for "lemons": quality uncertainty and the market mechanism," Quarterly Journal of Economics, 84, 488-500.

AlPert, M., And H. RAIFFA (1982): “A Progress Report on the Training of Probability Assessors," in Judgment Under Uncertainty: Heuristics and Biases, ed. by D. Kahneman, and A. Tversky, pp. 294-305, Cambridge. Cambridge University Press. 
Bester, H., and K. Ritzberger (2001): "Strategic Pricing, Signaling, and Costly Information Acquisition," International Journal of Industrial Organization, 19, 13471361.

Bond, E. W. (1982): "A Direct Test of the "Lemons" Model: The Market for Used Pickup Trucks," American Economic Review, 72, 836-840.

Buehler, R., D. Griffin, And M. Ross (1994): "Exploring the Planning Fallacy: Why People Underestimate Their Task Completion Times," Journal of Personality and Social Psychology, 67, 366-381.

ChO, I. K., AND D. M. KREPS (1987): “Signaling Games and Stable Equilibria," Quarterly Journal of Economics, 102, 179-221.

Clayson, D. E. (2005): "Performance Overconfidence: Metacognitive Effects or Misplaced Student Expectations," Journal of Marketing Education, 27, 122-129.

Crowson, D. C., R. Crowson, And Y. Ren (2007): "How to Manage an Overconfident Newsvendor," Working Paper, University of Texas at Dallas.

DE LA Ros A, L. E. (2011): "Overconfidence and moral hazard," Games and Economic Behavior, 73(2), $429-451$.

Ellingsen, T. (1997): "Price Signals Quality: The Case of Perfectly Inelastic Demand," International Journal of Industrial Organization, 19, 1347-1361.

EySTER, E., AND M. RABIN (2005): “Cursed Equilibrium,” Econometrica, 73, 16231672.

FAnG, H., AND G. Moscarini (2005): “Morale hazard," Journal of Monetary Economics, 52, 749 - 777.

Genesove, D. (1993): “Adverse Selection in the Wholesale Used Car Market," Journal of Political Economy, 101, 644-665.

GrubB, M. D. (2009): “Selling to Overconfident Consumers,” American Economic Review, 99, 1770-1807.

KeSSLER, A. S. (2001): "Revisiting the Lemons Market," International Economic Review, 42, 25-41.

LEVIN, J. (2001): "Information and the Market for Lemons," RAND Journal of Economics, 32, 657-666. 
LEWIS, G. (2011): “Asymmetric Information, Adverse Selection, and Online Disclosure: The Case of Ebay Motors," American Economic Review, 101, 1535-1546.

Rothschild, M., And J. Stiglitz (1976): "Equilibrium in Competitive Insurance Markets: An Essay on the Economics of Imperfect Information," The Quarterly Journal of Economics, 90, 629-649.

SAndroni, A., And F. SQuintani (2007): "Overconfidence, Insurance, and Paternalism," American Economic Review, 97, 1994-2004.

SOLL, J. B., AND J. KLAYMAN (2004): “Overconfidence in Interval Estimates," Journal of Experimental Psychology. Learning, Memory, and Cognition, 30, 299-314.

Voorneveld, M., And J. W. Weibull (2011): “A Scent of Lemon-Seller Meets Buyer with a Noisy Quality Observation"," Games, 2, 163-186.

WiLSON, C. (1980): “The Nature of Equilibrium in Markets with Adverse Selection," Bell Journal of Economics, 11, 108-130. 